\title{
The fluorescence of resin-based composites: An analysis after ten years of aging
}

\author{
Christian KLEIN ${ }^{1,2}$, Diana WOLFF ${ }^{1}$, Christiane VON OHLE ${ }^{1}$ and Christian MELLER ${ }^{1}$ \\ ${ }^{1}$ Department of Conservative Dentistry, Periodontology and Endodontology, University Center of Dentistry, Oral Medicine and Maxillofacial Surgery, \\ University Hospital Tübingen, Tübingen, Germany \\ ${ }^{2}$ Private practice Meller Zahngesundheit, Waiblingen, Germany \\ Corresponding author, Christian KLEIN; E-mail: Christian.Klein@med.uni-tuebingen.de
}

\begin{abstract}
The long-term preservation of fluorescence qualities of resin-based composite (RBC) restorations is an absolute condition for the implementation of the fluorescence-aided identification technique (FIT) in dentistry and forensic medicine. Therefore, this study assessed the fluorescence of 244 color shades of 16 commercially available RBC brands with a monochromator-based multimode microplate reader. The specimens were stored in the dark at room temperature and reassessed ten years after the initial investigation. The mean intensity of the fluorescence maxima decreased from $(31,030 \pm 936)$ RFU to $(22,027 \pm 632)$ RFU. Linear regression resulted in $\mathrm{r}^{2}=0.972$ and a slope $=0.701 \pm 0.005$. The fluorescence intensity of the tested RBCs dropped to about $70 \%$ of the initial intensity independent of the brand, color shade and initial fluorescence intensity. On the basis of this in vitro 10-year data set, we assume that in vivo $\mathrm{RBC}$ fluorescence is also suitable for the detection and differentiation of clinically aged RBC restorations by FIT.
\end{abstract}

Keywords: Resin-based composite, Fluorescence, Fluorescence-aided identification technique, Aging, Restauration removal

\section{INTRODUCTION}

Over the past decades fluorescence has become a powerful diagnostic tool in life sciences and medicine and often replaces radioactive labeling in various applications. Examples for the latter are automated sequencing of DNA, fluorescence-activated cell sorting, gel electrophoresis, real-time PCR, and fluorescence microscopy ${ }^{1)}$.

The widespread replacement of amalgam by toothcolored resin-based composites $(\mathrm{RBCs})^{2}$ has made the subsequent removal procedures of the RBC more complicated time-consuming and consequently less reliable $^{3-6)}$. Interestingly, forensic medical experts ${ }^{7-9)}$ recognized the benefits of fluorescence for the detection of RBC earlier than dentists ${ }^{10-12)}$. Meller and Klein demonstrated that the majority $(>80 \%)$ of the $\mathrm{RBC}$ brands and shades showed a fluorescence intensity higher than the intensity of natural dental hard tissues ${ }^{13,14)}$, which is the basic requirement for the implementation of the so-called "fluorescence-aided identification technique" (FIT).

FIT has been proven to facilitate the detection and discrimination of $\mathrm{RBC}$ restorations from tooth substance ${ }^{15,16)}$, as well as the removal of orthodontic brackets ${ }^{17,18)}$, trauma splints ${ }^{19,20)}$ and RBC restaurations ${ }^{21)}$. Since $\mathrm{RBC}$ restorations are expected to be of clinical service for many years, removal may only be necessary after long-term in vivo periods. Therefore, the long-term preservation of their fluorescence properties is crucial for the serviceability of FIT in dentistry and forensic medicine.

Color figures can be viewed in the online issue, which is available at J-STAGE.

Received Sep 25, 2019: Accepted Feb 12, 2020

doi:10.4012/dmj.2019-320 JOI JST.JSTAGE/dmj/2019-320
Moreover, the fluorescence of tooth colored dental materials plays, from a metameric point of view ${ }^{13)}$, an important role in the esthetic integration of tooth colored restorations into the natural dentition. $\mathrm{RBC}$ restorations may match the color of the natural teeth right after placement when observed under different light sources (e.g. artificial light or sunlight), but they may lose this property when the restoration gets older. In such cases, 'fluorescence-aided metameric failure' becomes apparent, as a consequence of a visual color mismatch of the composite restoration with the surrounding natural tooth structure.

Previous studies, reporting a gradual loss of the fluorescence properties of RBC after aging, are of little informative value due to small sample sizes and artificially conducted aging procedures ${ }^{22-24)}$. Consequently, a better knowhow about the fluorescence properties of RBC over time is needed. The aim of the present study was to assess the alteration of the fluorescence properties of a vast sample of current commercially available RBC shades after a storage period of ten years. The null hypothesis was that there is no difference between the initial situation and the situation after ten years.

\section{MATERIALS AND METHODS}

\section{Materials}

In the present study a total of 244 different shades of 16 widely used and available brands of RBCs were analyzed. Materials included some of the most commonly used brand names for composites employed by dentists worldwide in the past 10 years: Miris ${ }^{\circledR} 2$ (ColtèneWhaledent, Altstätten, Switzerland), Esthet- $\mathrm{X}^{\circledR} \mathrm{HD}$, 
Ceram-X ${ }^{\circledR}$ Duo, Spectrum ${ }^{\circledR}$ TPH3 (Dentsply DeTrey, Konstanz, Germany), EcuSphere ${ }^{\circledR}$ (DMG ChemischPharmazeutische Fabrik, Hamburg, Germany), ENAMEL Plus HFO/HRi ${ }^{\circledR}$ (GDF, Rosbach, Germany), Venus $^{\circledR}$, Venus ${ }^{\circledR}$ Diamond, Charisma ${ }^{\circledR}$ (Heraeus Kulzer, Hanau, Germany), Tetric EvoCeram ${ }^{\circledR}$, IPS Empress ${ }^{\circledR}$ Direct (Ivoclar-Vivadent, Schaan, Lichtenstein), Filtek $^{\mathrm{TM}}$ Supreme XT , Filtek ${ }^{\mathrm{TM}}$ Z250 (3M-Espe Dental Products, St. Paul, MN, USA), Amaris ${ }^{\circledR}$ and Grandio ${ }^{\circledR}$ (VOCO, Cuxhaven, Germany).

\section{Methods}

Based on a standardized procedure every shade of each brand was individually packed (5 $\mathrm{mm}$ thick) into 96-well black microplates (Corning, Lowell, WA, USA) and flattened with a microscope $3 \times 1$ inch glass slide $(\mathrm{R}$. Langenbrinck, Emmendingen, Germany) prior to light polymerization with a curing lamp (Bluephase ${ }^{\circledR}$, Ivoclar Vivadent) for $40 \mathrm{~s}$ at a maximum output of $(1,200 \pm 100)$ $\mathrm{mW} / \mathrm{cm}^{2}$. By doing so a reproducible, uniform, plane, shiny composite surface was achieved for every sample.

Fluorescence measurements were done $24 \mathrm{~h}$ later at $(37.0 \pm 0.5)^{\circ} \mathrm{C}$ using a monochromator-based microplate reader Synergy ${ }^{\mathrm{TM}}$ MX operated with the Gene $5^{\mathrm{TM}} 3.01$ software (both BioTek Instruments, Bad Friedrichshall, Germany). The instrument was calibrated with a $0.001 \%$ fluorescein disodium salt solution. The gain factor of the instrument was set to 84 . The samples were excited with a high energy xenon flash lamp positioned at an angle to the well for excitation, while the emission beam came from the top. The vertical distance was $4 \mathrm{~mm}$ and the column offset was $0 \mathrm{~mm}$. The microplate reader independently repeated the measurement of each excitation/emission combination ten times and presented the result as mean of the ten consecutive measurements. The delay between the measurements was $1 \mathrm{~ms}$ and the delay after plate movement $100 \mathrm{~ms}$. During the pre-scan, the excitation wavelength was set between 250 and $800 \mathrm{~nm}$ in $50 \mathrm{~nm}$ steps and a bandwidth of $9 \mathrm{~nm}$. During the effective scan, the excitation wavelength was set between 350 and 450 $\mathrm{nm}$ in $5 \mathrm{~nm}$ steps and a bandwidth of $9 \mathrm{~nm}$. The emission wavelength was set during both scans between 300 and $900 \mathrm{~nm}$ in $5 \mathrm{~nm}$ steps and a bandwidth of $9 \mathrm{~nm}$.

Subsequently, the specimens were stored at room temperature in the dark and re-assessed after ten years at $(37.0 \pm 0.2)^{\circ} \mathrm{C}$ with the monochromator-based microplate reader Cytation ${ }^{\mathrm{TM}} 5$, which was operated with the Gene $5^{\mathrm{TM}} 3.05$ software (both BioTek Instruments). The instrument was calibrated with a $0.001 \%$ fluorescein disodium salt solution. The gain factor of the instrument was set to 54. By doing this, the same fluorescence intensity value was achieved in relative fluorescence units (RFU) as ten years before. Again, the specimens were excited with a high energy xenon flash lamp in an angle to the well for excitation, while the emission beam was directed from the top. The vertical distance was 4 $\mathrm{mm}$ and the column offset was $0 \mathrm{~mm}$. The microplate reader independently repeated the measurement of each excitation/emission combination ten times and presented the result as mean of the ten consecutive measurements.
The delay between the measurements was $1 \mathrm{~ms}$ and the delay after plate movement $100 \mathrm{~ms}$. The excitation wavelength was set between $250 \mathrm{~nm}$ and $625 \mathrm{~nm}$ and the emission wavelength between $300 \mathrm{~nm}$ and $700 \mathrm{~nm}$, both in $5 \mathrm{~nm}$ steps and a bandwidth of $9 \mathrm{~nm}$.

\section{Data analysis}

The fluorescence of RBC shades can be characterized by its fluorescence maximum, i.e. its intensity in RFU and its corresponding excitation and emission wavelength ${ }^{13,14)}$. Therefore, these three parameters were evaluated at baseline and after ten years.

To assess the changes in the excitation and emission wavelength of the intensity maximum, the RBC shades were rated in three categories: Category I included all shades where the intensity maximum showed no difference in the corresponding excitation and emission wavelength after ten years. Category II summarized all shades whose excitation and/or emission wavelength differed by $5 \mathrm{~nm}$, i.e. only one scanning step. Finally, category III included the shades whose excitation and/ or emission wavelength differed by more than $5 \mathrm{~nm}$, resulting in more than one scanning step.

Since there were differences between the excitation and emission wavelength of the intensity maximum after ten years, when evaluating the fluorescence intensity, the excitation/emission combination of the initial maximum was defined as baseline. Furthermore, 16 shades were excluded from further analysis. These shades showed fluorescence intensities of only 2,072 RFU or lower, and thus they were below the precision cut-off of the instruments. The fluorescence intensity after ten years was divided by the intensity of the initial maximum and the result expressed in percent of the initial fluorescence.

\section{Statistical analyses}

Statistical analyses were carried out with the software JMP 14.2 (SAS Institute, Cary, NC, USA). Firstly, the data (mean \pm standard error of the mean) was checked for conformity with a normal distribution with the ShapiroWilk W-test at $p>0.05$. To assess statistically significant differences between the test data, the Tukey's HSD test was performed at a significance level of $\alpha=0.05$. In addition, linear regression analysis of the fluorescence intensities was performed. The model intercept was constrained to $\mathrm{Y}=0$.

\section{RESULTS}

Sixty eight point four percent $(n=167)$ of altogether 244 RBC shades had excitation/emission combination changes that were classified as category I, $22.5 \%$ $(n=55)$ as category II and $9.1 \%(n=22)$ as category III. Nevertheless, there were differences between the brands (see Fig. 1).

Ten brands showed only classifications in the categories I and II: Esthet- $\mathrm{X}^{\circledR} \mathrm{HD}$ [93.6\% $(n=29)$ category I and 6.4\% $(n=2)$ category II], Empress ${ }^{\circledR}$ Direct $[87,5 \%$ $(n=7)$ category I and $12.5 \%(n=1)$ category II], Grandio ${ }^{\circledR}$ 


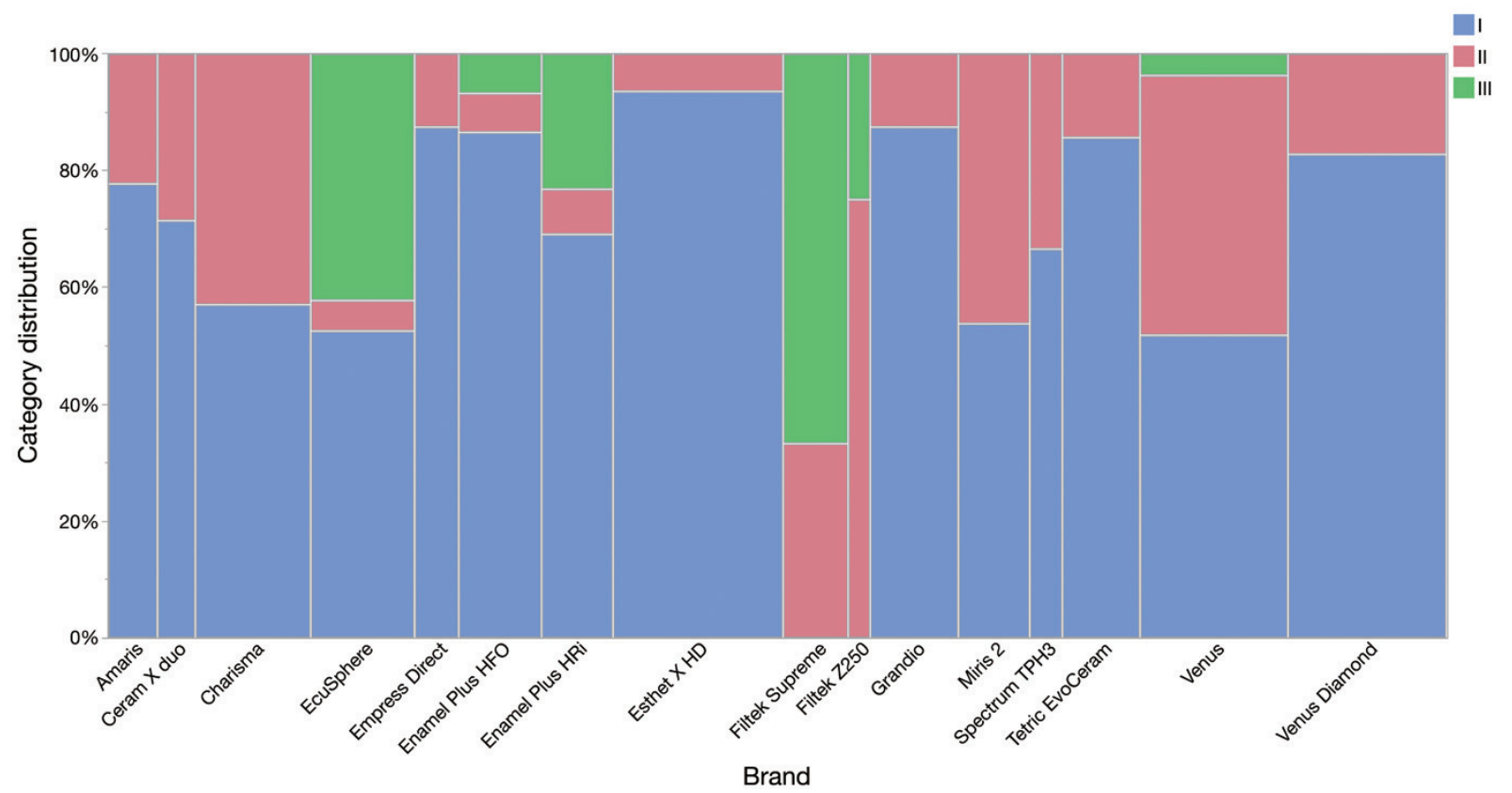

Fig. 1 Mosaic plot showing changes in the combination of excitation and emission wavelength of intensity maxima after ten years for the assessed brands divided into three categories: Category I - no differences in the excitation/emission wavelength after ten years, category II —a difference of 5 $\mathrm{nm}$ and one scanning step, and category III - a difference of more than $5 \mathrm{~nm}$ and more than one scanning step each.

Sixty eight point four percent $(n=167)$ of the brands showed changes in the excitation/emission combination that were classified as category I, $22.5 \%(n=55)$ as category II, and $9.1 \%(n=22)$ as category III.

[87.5\% $(n=14)$ category I and $12.5 \%(n=2)$ category II], Tetric EvoCeram ${ }^{\circledR}[85.7 \%(n=12)$ category I and $14.3 \%$ $(n=2)$ category II], Venus ${ }^{\circledR}$ Diamond $[82.8 \% \quad(n=24)$ category I and $17.2 \%(n=5)$ category II $]$, Amaris ${ }^{\circledR}[77.8 \%$ $(n=7)$ category I and $22.2 \%(n=2)$ category II], Ceram-X ${ }^{\circledR}$ Duo [71.4\% $(n=5)$ category I and $28.6 \%(n=2)$ category II], Spectrum ${ }^{\circledR T P H} 3$ [66.7\% $(n=4)$ category I and $33.3 \%$ $(n=2)$ category II], Charisma ${ }^{\circledR}[57.1 \%(n=12)$ category I and $42.9 \%(n=9)$ category II], and Miris ${ }^{\circledR} 2$ [53.9\% $(n=7)$ category I and $46.1 \%(n=6)$ category II].

Four brands showed classifications in all three categories: ENAMEL Plus HFO ${ }^{\circledR}[86.6 \%(n=13)$ category I, $6.7 \%(n=1)$ category II and $6.7 \%(n=1)$ category III], ENAMEL Plus HRi ${ }^{\circledR}[69.2 \%(n=9)$ category I, 7.7\% $(n=1)$ category II and 23.1\% $(n=3)$ category III], EcuSphere ${ }^{\circledR}$ $[52.6 \%(n=10)$ category I, 5.3\% $(n=1)$ category II and $42,1 \%(n=8)$ category III $]$, and $\mathrm{Venu}^{\circledR}[51.9 \% \quad(n=14)$ category I, $44.4 \%(n=12)$ category II and $3.7 \%(n=1)$ category III].

Two brands showed no classification in category I: Filtek $^{\mathrm{TM}}$ Z250 [75.0\% $(n=3)$ category II and 25.0\% $(n=1)$ category III] and Filtek ${ }^{\mathrm{TM}}$ Supreme XT [33.3\% $(n=4)$ category II and $66.7 \%(n=8)$ category III].

The following shades were excluded for the analysis of the fluorescence intensity change after ten years: EcuSphere ${ }^{\circledR}$ B3 (194 RFU), A4 (431 RFU), A1 (539 RFU), C3 (585 RFU), B1 (690 RFU), C1 (791 RFU), D2 (802
RFU), and B2 (986 RFU); Filtek ${ }^{\mathrm{TM}}$ Z250 A3.5 (1,082 RFU), A4 (1,266 RFU), A2 (1,428 RFU), and B3 (1430); Filtek $^{\mathrm{TM}}$ Supreme XT YT (1,220 RFU), A4D (1,859 RFU), B3D (1,911 RFU), and A3D (2,072 RFU). The mentioned RFU values represent the fluorescence intensity after ten years.

The change in fluorescence intensity after ten years at the excitation/emission combination of the initial maximum in percent is depicted in Fig. 2: Amaris ${ }^{\circledR}$ $(73 \pm 1) \%(n=9)$, Ceram $-\mathrm{X}^{\circledR}$ Duo $(90 \pm 2) \%(n=7)$, Charisma $^{\circledR}$ $(60.3 \pm 0.5) \% \quad(n=21), \quad$ EcuSphere ${ }^{\circledR} \quad(78.4 \pm 0.6) \% \quad(n=11)$, Empress $^{\circledR}$ Direct $(78 \pm 2) \%(n=8)$, ENAMEL Plus HFO ${ }^{\circledR}$ $(71 \pm 1) \%(n=15)$, ENAMEL Plus $\mathrm{HRi}^{\circledR}(75 \pm 1) \%(n=13)$, Esthet-X $\mathrm{X}^{\circledR}$ HD $(75.9 \pm 0.7) \%(n=31)$, Filtek ${ }^{\mathrm{TM}}$ Supreme XT $(78 \pm 4) \% \quad(n=8)$, Grandio $^{\circledR}(65.4 \pm 0.5) \% \quad(n=16)$, Miris $^{\circledR} 2$ $(72 \pm 1) \% \quad(n=13)$, Spectrum ${ }^{\circledR}$ TPH3 $\quad(74.7 \pm 0.6) \% \quad(n=6)$, Tetric EvoCeram ${ }^{\circledR}(74.8 \pm 0.6) \%(n=14)$, Venus $^{\circledR}(69 \pm 2) \%$ $(n=27)$, and Venus ${ }^{\circledR}$ Diamond $(72.4 \pm 0.4) \%(n=29)$.

With $(90 \pm 2) \%$ Ceram- $X^{\circledR}$ Duo showed the lowest average intensity loss of all $15 \mathrm{RBC}$ brands. This loss was significantly lower $(p<0.0001)$ than the second lowest loss observed with Empress ${ }^{\circledR}$ Direct, i.e. $(78 \pm 2) \%$. On the other side Charisma ${ }^{\circledR}$ showed the greatest intensity loss with $(60.3 \pm 0.5) \%$. This was not significantly different $(p<0.237)$ to the loss of Grandio ${ }^{\circledR}$ with $(65.4 \pm 0.5) \%$, but significantly larger $(p<0.001)$ than the loss observed with Venus $^{\circledR}$ with $(69 \pm 2) \%$. The other brands between Venus ${ }^{\circledR}$ 


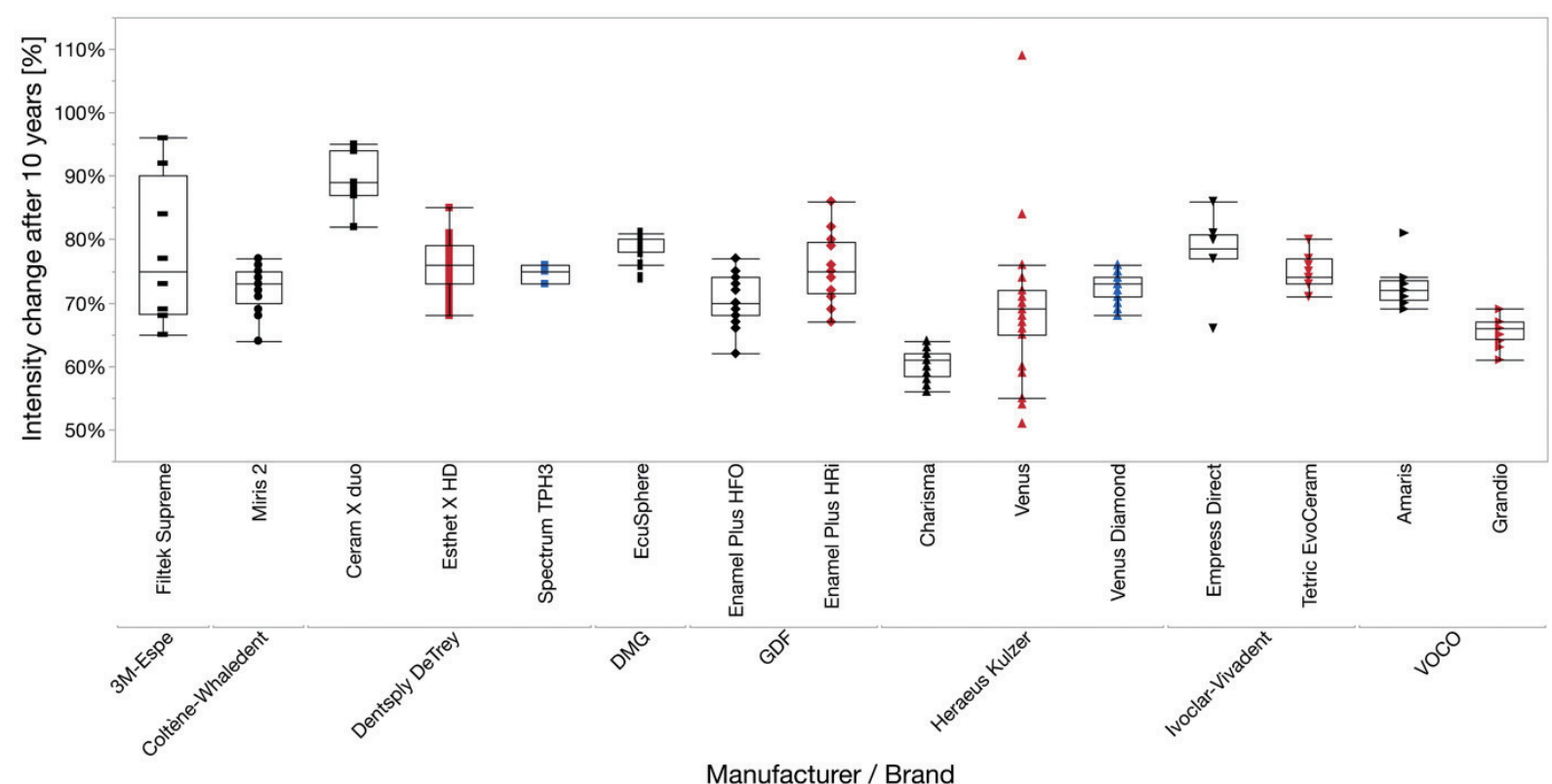

Fig. 2 Boxplot showing the change of the fluorescence intensity for the excitation/emission combination of the initial maximum after ten years in percent of the initial intensity.

Brands of the same manufacturer share the same symbol with a different color for the respective brand. The depicted symbols and colors are the same as in Fig. 3. Therefore, this figure can be used for visual orientation.

Table 1 Intensity change after ten years expressed in percent of the initial intensity (mean \pm standard error of the mean).

\begin{tabular}{|c|c|c|}
\hline Brand & Intensity change [\%] & $n$ \\
\hline Ceram-X $\mathrm{X}^{\circledR}$ Duo & $90( \pm 2)^{\mathrm{A}}$ & 7 \\
\hline EcuSphere $^{\circledR}$ & $78.4( \pm 0.6)^{\mathrm{B}}$ & 11 \\
\hline Empress $^{\circledR}$ Direct & $78( \pm 2)^{\mathrm{B}, \mathrm{C}}$ & 8 \\
\hline Filtek $^{\mathrm{TM}}$ Supreme XT & $78( \pm 4)^{\mathrm{B}, \mathrm{C}}$ & 8 \\
\hline Esthet- $\mathrm{X}^{\circledast} \mathrm{HD}$ & $75.9( \pm 0.7)^{\mathrm{B}, \mathrm{C}}$ & 31 \\
\hline ENAMEL Plus HRi ${ }^{\circledR}$ & $75( \pm 1)^{\mathrm{B}, \mathrm{C}}$ & 13 \\
\hline Tetric EvoCeram ${ }^{\circledR}$ & $74.8( \pm 0.6)^{\mathrm{B}, \mathrm{C}, \mathrm{D}}$ & 14 \\
\hline Spectrum ${ }^{\circledR} \mathrm{TPH} 3$ & $74.7( \pm 0.6)^{\mathrm{B}, \mathrm{C}, \mathrm{D}}$ & 6 \\
\hline Amaris $^{\circledR}$ & $73( \pm 1)^{\mathrm{B}, \mathrm{C}, \mathrm{D}, \mathrm{E}}$ & 9 \\
\hline Venus ${ }^{\circledR}$ Diamond & $72.4( \pm 0.4)^{\mathrm{B}, \mathrm{C}, \mathrm{D}}$ & 29 \\
\hline Miris $^{\circledR 2}$ & $72( \pm 1)^{\mathrm{B}, \mathrm{C}, \mathrm{D}}$ & 13 \\
\hline ENAMEL Plus HFO & $71( \pm 1)^{\mathrm{C}, \mathrm{D}, \mathrm{E}}$ & 15 \\
\hline Venus ${ }^{\circledR}$ & $69( \pm 2)^{\mathrm{D}, \mathrm{E}}$ & 27 \\
\hline Grandio $^{\circledR}$ & $65.4( \pm 0.5)^{\mathrm{E}, \mathrm{F}}$ & 16 \\
\hline Charisma $^{\circledR}$ & $60.3( \pm 0.5)^{\mathrm{F}}$ & 21 \\
\hline
\end{tabular}

Groups linked by the same letter do not differ statistically significantly.

with $(69 \pm 2) \%$ and Empress ${ }^{\circledR}$ Direct with $(78 \pm 2) \%$ showed no clinically relevant differences. Statistical details can be found in Table 1.

The linear regression of the fluorescence intensity after ten years at the excitation/emission combination of the initial maximum $v s$. the initial maximum intensity resulted in a slope of $0.701 \pm 0.005(p<0.001)$ and a Pearson correlation coefficient of 0.972 (Fig. 3). 


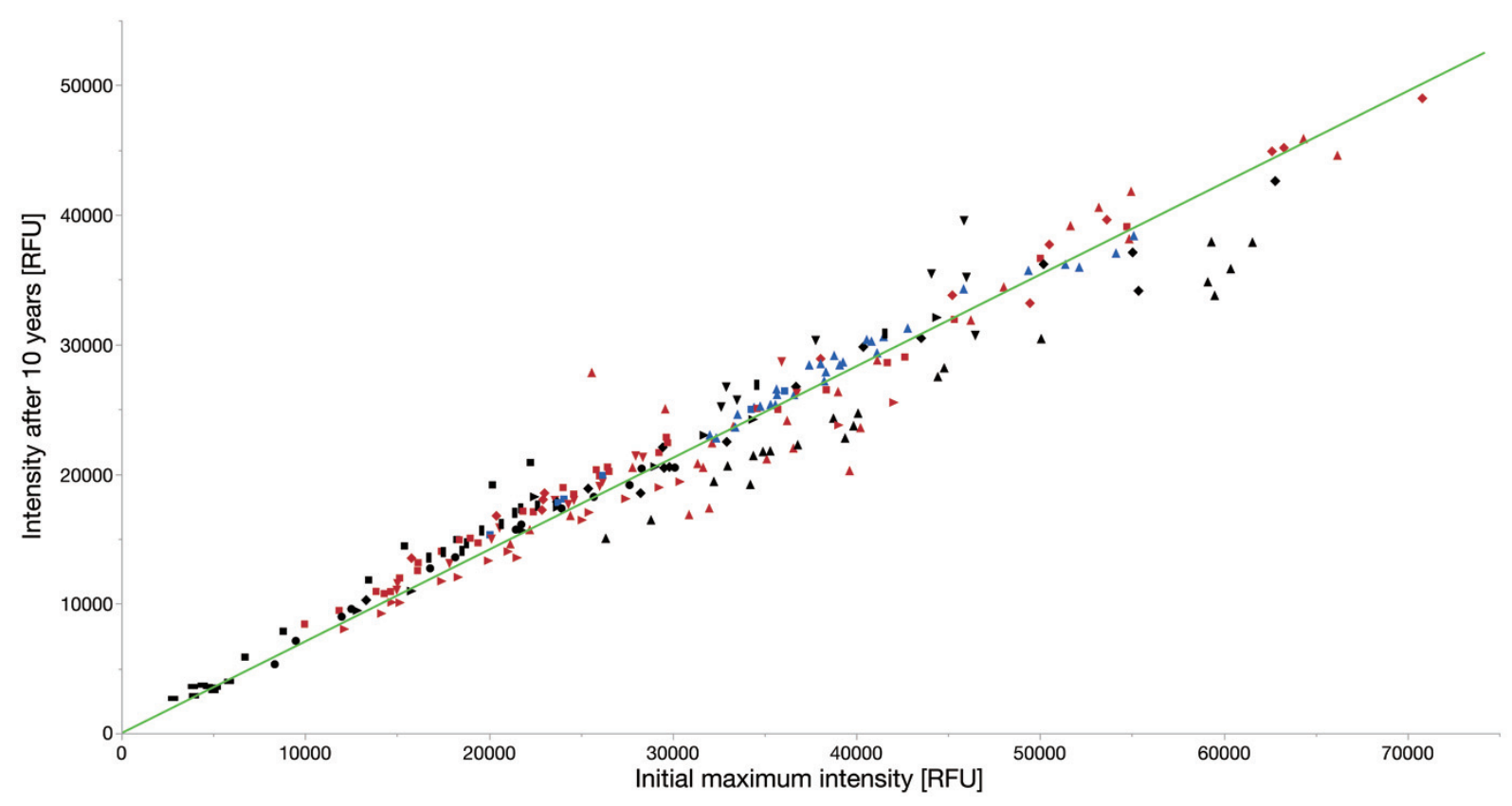

Fig. 3 Scatter plot showing the fluorescence intensity after ten years at the excitation/emission combination of the initial maximum vs. the initial maximum intensity in RFU.

The linear regression with an intercept constrained to $\mathrm{Y}=0$ resulted in a slope of $0.701 \pm 0.005(p<0.001)$ and a Pearson correlation coefficient of 0.972. The depicted symbols and colors are the same as in Fig. 2. Therefore, the latter can be used for visual orientation.

\section{DISCUSSION}

The aim of this study was to examine a possible alteration of the fluorescence properties of $244 \mathrm{RBC}$ shades after ten years of storage. After this period the fluorescence intensity distribution still showed a peaklike structure ${ }^{13,14)}$, and therefore, its description by the parameters of the fluorescence maximum (i.e. excitation wavelength, emission wavelength and its intensity) was still appropriate.

The shift of the excitation/emission wavelength combination was low. Only $9.1 \%$ of the shades showed an alteration larger than one scan step $(5 \mathrm{~nm})$ and the majority of the shades representing more than two thirds showed no change at all. Alterations larger than $5 \mathrm{~nm}$ were observed with shades that showed low fluorescence intensities (e.g. Filtek ${ }^{\mathrm{TM}} \mathrm{Z} 250$ ). Therefore, measuring inaccuracy of the microplate readers was likely, justifying the exclusion of the 16 shades with the lowest intensity from further evaluation.

In the remaining 228 specimens a reduction in the fluorescence intensity was seen. The linear regression including all shades showed a high correlation (0.972) and a slope of $0.701 \pm 0.005$ (Fig. 3) even though differences between the brands were present [i.e. Ceram- $\mathrm{X}^{\circledR}$ Duo with the lowest $(90 \pm 2) \%$ and Charisma ${ }^{\circledR}$ with the greatest $(60.3 \pm 0.5) \%$ average intensity loss (Fig. $2)$ ]. Consequently, when applying the presented storage conditions, the fluorescence intensity of the assessed RBCs dropped to approximately $70 \%$ of the initial values after ten years.

The samples were stored for ten years in the dark and at room temperature. In doing so, the room was not additionally air-conditioned, therefore, the temperature was subject to seasonal changes in the range of 20 to $35^{\circ} \mathrm{C}$. In contrast to other studies that investigated color stability, translucency or fluorescence of RBC, no accelerated or artificial aging was applied here.

One way to achieve accelerated aging is to use a weatherometer. These devices were developed to evaluate the ability of papers, inks, paints or varnishes to retain their properties when exposed to inclement weather. With this procedure the RBC materials were exposed to UV light, changes in temperature and humidity ${ }^{22,23,25-28)}$. Some studies applied ASTM standards $^{23,26)}$. Other studies used thermocycling as a method to accelerate the aging process ${ }^{24,29}$. By this the samples were immersed in water with different temperatures (usually 5 and $55^{\circ} \mathrm{C}$ ) and different dwell times. The more cycles are repeated, the more pronounced is the artificial aging process.

Knowledge concerning the fluorescent compounds and the way they are incorporated in the RBC are prerequisite to asses an appropriate artificial aging process. Uo et al. melted rare earth oxides with glass filler particles to obtain fluorescent $\mathrm{RBC}^{30}$. Rattle and Bush demonstrated that three commercial RBC (i.e. Filtek $^{\mathrm{TM}}$ Supreme, QuiXX ${ }^{\circledR}$, and Tetric Ceram ${ }^{\circledR}$ ) lost their fluorescence properties above $300^{\circ} \mathrm{C}^{31}$. This indicates that their fluorescence is based on organic compounds, 
which are lost due to pyrolysis. Park et al. incorporated an organic fluorescent whitening agent (i.e. 1,4-bis(2benzoxazolyl)naphthalene, CAS No 5089-22-5) in varying concentrations ( 0.01 to $0.1 \%$ ) in an experimental resin matrix and measured a concentration-dependent fluorescence intensity with an emission maximum at $450 \mathrm{~nm}^{29)}$. Rare earth hybrid materials may be a further method to achieve fluorescent $\mathrm{RBC}^{32)}$. Fluorescent complexes of rare earth ions with organic ligands can be polymerized into the resin matrix via a spacer molecule with methacrylate function. Since the manufacturers do not specify the fluorescence compounds and the way they are incorporated in their products, it is not possible or at least hypothetical to determine an aging method which simulates the situation in the mouth.

All studies assessing fluorescence intensity after accelerated aging showed a reduction in fluorescence intensity in the majority of the RBC examined ${ }^{22-24)}$. The only exception was Filtek ${ }^{\mathrm{TM}}$ Supreme: Lee et al. were unable to detect any initial fluorescence in Filtek ${ }^{\mathrm{TM}}$ Supreme. Consequently, they did not measure any fluorescence after the aging process ${ }^{22)}$. Jablonski et al. measured initial fluorescence in Filtek ${ }^{\mathrm{TM}}$ Supreme and stated that it was the only RBC showing no negative effect (i.e. no reduction of its intensity) after thermocycling. However, our data set on Filtek ${ }^{\mathrm{TM}}$ Supreme showed a reduction in fluorescence intensity after ten years of storage to $(78 \pm 4) \% \quad(n=8)$ of the initial intensity. This corresponds roughly with the mean reduction of all RBC examined in the present study. As Filtek ${ }^{\mathrm{TM}}$ Supreme shows a poor initial fluorescence ${ }^{13,14,22-24)}$, a possible explanation for the divergent results might be the varying degrees of precision of the different measurement methods used.

Some studies have also used UV light exposure for artificial aging. Lee et al. performed artificial aging with a weatherometer and a UV light exposure of 0.55 $\mathrm{W} / \mathrm{m}^{2} / \mathrm{nm}$ at $340 \mathrm{~nm}^{22)}$, whereas Takahashi et al. used a weatherometer and a UV light exposure of 0.35 $\mathrm{W} / \mathrm{m}^{2} / \mathrm{nm}$ at $340 \mathrm{~nm}^{23)}$. As a result, Lee et al. measured no remaining fluorescence after the artificial aging process and Takahashi et al. recognized a reduction to $23.5 \%$ of the original fluorescence intensity with Charisma ${ }^{\circledR}$ and $38.1 \%$ with Esthet- $\mathrm{X}^{\circledR}$ HD. This is a considerably greater reduction as measured by Jablonski et al. after thermocycling without UV light exposure ${ }^{24)}$. In their study, Charisma ${ }^{\circledR}$ showed a reduction to $54.2 \%$ and Esthet- $\mathrm{X}^{\circledR} \mathrm{HD}$ to $84.9 \%$ of the initial fluorescence intensity. In the present study Charisma ${ }^{\circledR}$ showed a reduction to $(60.3 \pm 0.5) \%(n=21)$ and Esthet- $\mathrm{X}^{\circledR} \mathrm{HD}$ to $(75.9 \pm 0.7) \%(n=31)$ of the initial fluorescence intensity. The differences between the study by Jablonski et al. and the present study probably result not only from the different aging methods but also from the fact that Jablonski et al. examined only two color shades and in the present study all available shades of a brand were evaluated. Nevertheless, the present study is in line with Jablonski et al. who state that the extreme conditions under UV light are not suitable to simulate the aging process in the oral environment. This aspect is further supported by the fact that photo bleaching of fluorescent dyes is described as a complication in the use of fluorescence detection in life sciences and medicine ${ }^{1)}$. Since the fluorescent dyes used by the manufacturers are not disclosed, the discussion about further factors and their influence on the fluorescence intensity is only possible on a theoretical basis. In addition to photo bleaching, the diffusion of (dye) molecules and the hydrolysis of bonds must be considered in the wet environment of the oral cavity. Diffusion depends on the size and hydrophilicity of the dye molecules. The smaller and more hydrophilic they are, the faster they are dissolved from the RBC. The hydrolysis rate of organic RBC compounds, whether dye or spacer molecules, with which the dyes may be polymerized into the resin matrix depends on the unknown nature of these compounds. In photo bleaching and diffusion, in particular, the effect is greatest on the RBC restoration surface. Due to the storage conditions used in the present study (i.e., dry and dark), diffusion and photo bleaching can be excluded as influencing factors on fluorescence intensity. In this sense, the loss of fluorescence intensity at the restoration surface may be even greater, so that the fluorescenceaided metameric failure is underestimated by this study. However, the present study does not address the effects of fluorescence intensity loss due to aging on the esthetics of $\mathrm{RBC}$ restorations. Klein et al. have demonstrated that the removal of newly placed and thus not aged toothcolored RBC restorations can be improved by applying FIT using the fiber optic of the handpiece for fluorescence excitation $^{21)}$. Therefore, it is of interest whether FIT can prevent $\mathrm{RBC}$ residues from being left on teeth or whether unnecessary loss of tooth structure takes place when tooth-colored $\mathrm{RBC}$ restorations are removed that have been in situ for many years. In contrast to the esthetics of the restoration, the effectiveness of FIT is not influenced by the fluorescence on the restoration surface, but on the interface between tooth and restoration. Photo bleaching and diffusion play a minor role at this interface. Thus, the storage conditions of the present study allow to estimate the influence of the fluorescence intensity loss on FIT, but only to a limited extent on the esthetics of the restoration. The latter was therefore not further investigated in this study.

\section{CONCLUSION}

Within the limitation of this in vitro study, it can be stated that after ten years of storage the fluorescence intensity of the tested RBC dropped to about $70 \%$ of the initial intensity, independent of the brand, the color shade, and the initial fluorescence intensity. Therefore, the null hypothesis was rejected. We conclude that if a material with sufficient initial fluorescence intensity has been used, FIT can be a valuable tool for the detection, discrimination and subsequent removal of $\mathrm{RBC}$ restorations in vivo at least for up to ten years after placement. 


\section{CONFLICT OF INTEREST}

The authors declare that no conflict of interest exists. There is no financial or personal relationship with any of the manufacturers of the resin composites included in the study, which could unduly affect the content of this paper. The study was performed and funded by the Department of Conservative Dentistry, Periodontology and Endodontology, University Center of Dentistry, Oral Medicine and Maxillofacial Surgery, University Hospital Tübingen, Germany.

\section{REFERENCES}

1) Goldys EM. Fluorescence applications in biotechnology and life science. 1st ed. Hoboken, NJ: Wiley-Blackwell; 2009. 416 p.

2) Eltahlah D, Lynch CD, Chadwick BL, Blum IR, Wilson NHF. An update on the reasons for placement and replacement of direct restorations. J Dent 2018; 72: 1-7.

3) Szep S, Baum C, Alamouti C, Schmidt D, Gerhardt T, Heidemann D. Removal of amalgam, glass-ionomer cement and compomer restorations: changes in cavity dimensions and duration of the procedure. Oper Dent 2002; 27: 613-620.

4) Mjör IA, Reep RL, Kubilis PS, Mondragon BE. Change in size of replaced amalgam restorations: a methodological study. Oper Dent 1998; 23: 272-277.

5) Krejci I, Lieber CM, Lutz F. Time required to remove totally bonded tooth-colored posterior restorations and related tooth substance loss. Dent Mater 1995; 11: 34-40.

6) Hunter AR, Treasure ET, Hunter AJ. Increases in cavity volume associated with the removal of class 2 amalgam and composite restorations. Oper Dent 1995; 20: 2-6.

7) Carson DO, Orihara Y, Sorbie JL, Pounder DJ. Detection of white restorative dental materials using an alternative light source. Forensic Sci Int 1997; 88: 163-168.

8) Clark DH, Ruddick RF. Post mortem detection of tooth coloured dental restorations by ultra violet radiation. Acta Med Leg Soc 1985; 35: 278-284.

9) Pretty IA, Smith PW, Edgar WM, Higham SM. The use of quantitative light-induced fluorescence (QLF) to identify composite restorations in forensic examinations. J Forensic Sci 2002; 47: 831-836.

10) Tani K, Watari F, Uo M, Morita M. Discrimination between composite resin and teeth using fluorescence properties. Dent Mater J 2003; 22: 569-580.

11) Lim YK, Lee YK. Fluorescent emission of varied shades of resin composites. Dent Mater 2007; 23: 1262-1268.

12) Hermanson AS, Bush MA, Miller RG, Bush PJ. Ultraviolet illumination as an adjunctive aid in dental inspection. $\mathrm{J}$ Forensic Sci 2008; 53: 408-411.

13) Meller C, Klein C. Fluorescence properties of commercial composite resin restorative materials in dentistry. Dent Mater J 2012; 31: 916-923.

14) Meller C, Klein C. Fluorescence of composite resins: A comparison among properties of commercial shades. Dent Mater J 2015; 34: 754-765.

15) Meller C, Connert T, Löst C, ElAyouti A. Reliability of a fluorescence-aided identification technique (FIT) for detecting tooth-colored restorations: an ex vivo comparative study. Clin
Oral Investig 2017; 21: 347-355.

16) Kiran R, Chapman J, Tennant M, Forrest A, Walsh LJ. Detection of tooth-colored restorative materials for forensic purposes based on their optical properties: an in vitro comparative study. J Forensic Sci 2019; 64: 254-259.

17) Schott TC, Meller C. A new fluorescence-aided identification technique (FIT) for optimal removal of resin-based bracket bonding remnants after orthodontic debracketing. Quintessence Int 2018; 49: 809-813.

18) Salomao FM, Rocha RS, Franco LM, Sundfeld RH, Bresciani E, Fagundes TC. Auxiliary UV light devices for removal of fluorescent resin residues after bracket debonding. J Esthet Restor Dent 2019; 31: 58-63.

19) Dettwiler C, Meller C, Eggmann F, Saccardin F, Kuhl S, Filippi $\mathrm{A}$, et al. Evaluation of a fluorescence-aided identification technique (FIT) for removal of composite bonded trauma splints. Dent Traumatol 2018; 34: 353-359.

20) Saccardin F, Ortiz V, Dettwiler C, Connert T, Filippi A. Removal of composite-bonded trauma splints using the fluorescence-aided identification technique (FIT). Quintessence Int 2019; 50: 456-460.

21) Klein C, Babai A, von Ohle C, Herz M, Wolff D, Meller C. Minimally invasive removal of tooth-colored restorations: evaluation of a novel handpiece using the fluorescence-aided identification technique (FIT). Clin Oral Investig 2020; 24: 2735-2743.

22) Lee YK, Lu H, Powers JM. Changes in opalescence and fluorescence properties of resin composites after accelerated aging. Dent Mater 2006; 22: 653-660.

23) Takahashi MK, Vieira S, Rached RN, de Almeida JB, Aguiar M, de Souza EM. Fluorescence intensity of resin composites and dental tissues before and after accelerated aging: a comparative study. Oper Dent 2008; 33: 189-195.

24) Jablonski T, Takahashi MK, Brum RT, Rached RN, Souza EM. Comparative study of the fluorescence intensity of dental composites and human teeth submitted to artificial aging. Gen Dent 2014; 62: 37-41.

25) Lee YK, Lu H, Powers JM. Optical properties of four esthetic restorative materials after accelerated aging. Am J Dent 2006; 19: 155-158.

26) Pires-de-Souza Fde C, Garcia Lda F, Hamida HM, Casemiro LA. Color stability of composites subjected to accelerated aging after curing using either a halogen or a light emitting diode source. Braz Dent J 2007; 18: 119-123.

27) Schulze KA, Marshall SJ, Gansky SA, Marshall GW. Color stability and hardness in dental composites after accelerated aging. Dent Mater 2003; 19: 612-619.

28) Schulze KA, Tinschert J, Marshall SJ, Marshall GW. Spectroscopic analysis of polymer-ceramic dental composites after accelerated aging. Int J Prosthodont 2003; 16: 355-361.

29) Park MY, Lee YK, Lim BS. Influence of fluorescent whitening agent on the fluorescent emission of resin composites. Dent Mater 2007; 23: 731-735.

30) Uo M, Okamoto M, Watari F, Tani K, Morita M, Shintani A. Rare earth oxide-containing fluorescent glass filler for composite resin. Dent Mater J 2005; 24: 49-52.

31) Rattle CN, Bush MA. Fluorescence and structural degradation in composite resins as a function of temperature. J Forensic Sci 2009; 54: 433-438.

32) Yan B. Photofunctional Rare Earth Hybrid Materials. 1st ed. Singapore: Springer; 2017. $261 \mathrm{p}$. 